\title{
A FICÇÃO EM NOVE NOITES
}

\author{
THE FICTION IN NOVE NOITES
}

\section{Daniela Silva de Freitas ${ }^{1}$}

Resumo: Vivemos hoje um boom de livros sobre a memória, seja ela pública ou privada: autobiografias, biografias, metaficções historiográficas. É neste contexto histórico-cultural que se insere o romance que o presente artigo se propõe a analisar. Nove Noites, de Bernardo Carvalho, publicado em 2002, parece ser parte de uma busca do autor pela reafirmação do valor da ficção. Apropriando-se, de maneira vertiginosa, de formas literárias que se articulam a partir de um limite mais próximo da realidade - da biografia, da autobiografia e da metaficção historiográfica -, o romance emprega a linguagem e as estratégias destas formas literárias de modo a fazer com que o pacto com a ficção sempre prevaleça sobre o pacto com a realidade. Este artigo tenta descrever como esse processo acontece no romance.

Palavras-chave: auto/biografia; meta/ficção; memória.

Abstract: Autobiographies, biographies, historiographic metafictions: today we witness a boom of publications on public or private memories. Published in this context, Nove Noites, a novel written by Bernardo Carvalho, seems to be part of the author's attempt to foreground the value of fiction. In order to do so, the novel appropriates some of the language and strategies employed by literary forms that keep a close link to reality (such as biographies, autobiographies and historiographic metafictions), but uses them in a way that the author's pact with fiction always prevails over his commitment to reality. This article tries to describe and comment on how this pact with fiction is enacted in the novel.

Key-words: auto/biography; meta/fiction; memory.

Com a chegada "do fim do século XX, e com ele do fim do milênio, nosso olhar se volta para trás com mais frequência, numa tentativa de armazenar dados e de nos situarmos no curso do tempo". Isto é o que afirma Andreas Huyssen na introdução de seu livro Memórias do modernismo. Com as mudanças causadas por "acelerados processos técnicos que estão transformando as nossas vidas em muitos aspectos diferentes", com o enfraquecimento e a desestabilização da fronteira entre o passado e o presente e com a diminuição da dimensão experiencial do espaço, vivemos em meio à emergência da memória como uma preocupação político-cultural central em nossas sociedades contemporâneas (HUYSSEN, 1997, p. 12-18).

Esta "virada para o passado", argumenta o teórico, "se apresenta num grande contraste ao privilégio do futuro, tão característico de décadas anteriores da modernidade do século XX". Com a crise evidente da ideologia do progresso e da modernização, nosso "foco mudou de futuros presentes para passados presentes" (HUYSSEN, 2003, p.1 -11)2.

Em decorrência destas mudanças, vivemos numa época de "esgotamento de toda uma tradição de filosofias teleológicas sobre a história". Antes o discurso da história costumava "garantir a relativa estabilidade do passado no passado". Além disso,

\footnotetext{
${ }^{1}$ Doutora em Literatura, Cultura e Contemporaneidade pela Pontifícia Universidade Católica do Rio de Janeiro, mestre em Literaturas de Língua Inglesa pela Universidade do Estado do Rio de Janeiro, professora de Literaturas de Língua Inglesa na Universidade Federal de Alfenas. E-mail: danielasf@gmail.com; http://lattes.cnpq.br/ $\underline{7392114043080381}$

2 Tradução feita por mim, como a de todos os outros textos citados em inglês ou espanhol nas referências.
} 
nossas tradições, por mais que fossem frequentemente inventadas ou construídas e sempre baseadas em seleções e exclusões, moldavam nossa vida cultural e social. [...] Por cerca de dois séculos a história no ocidente foi bem sucedida em seu projeto de ancorar o presente cada vez mais transitório da modernidade em uma narrativa multifacetada, contudo forte, do tempo histórico.

Hoje, contudo, “este modelo já não funciona mais” (HUYSSEN, 2003, pp. 1-2).

Esta obsessão contemporânea com os discursos da memória, este privilégio dos "passados presentes" tem se refletido de forma muito forte na produção literária de todo o mundo. Vivemos hoje um boom de livros sobre a memória, seja ela pública ou privada: autobiografias, biografias, metaficções historiográficas. É neste contexto histórico-cultural que se insere o romance que o presente artigo se propõe a analisar, Nove Noites de Bernardo Carvalho, publicado em 2002.

Bernardo Carvalho parece bastante incomodado com o lugar que a ficção ocupa na literatura contemporânea dentro deste cenário da emergência dos discursos da memória. Em entrevista recente concedida ao blog da Companhia das Letras, ele diz que acha que a ficção está em baixa. E continua:

É claro que ela continua existindo com a mesma frequência e com a mesma quantidade de antes, mas já não pode dizer o seu nome impune. As pessoas precisam acreditar, hoje elas querem ser crentes. Isso fica óbvio na internet, que é um poço de imposturas. As pessoas querem ler ficção, mas sem esse rótulo, como se fosse não-ficção. (CARVALHO, 2013)

Falando de Nove Noites em uma outra entrevista, ele afirma que "o livro foi escrito num momento em que eu estava muito irritado com essa ideia de que a ficção vale menos do que os livros baseados em histórias reais, o que é uma tendência muito forte no mundo todo" (CARVALHO, 2011). O autor também expressa esta preocupação em outras entrevistas e num artigo publicado a partir de uma palestra que ele deu enquanto escritor residente da Universidade de Wisconsin no outono de 2009. O artigo foi sugestivamente intitulado de "Fiction as Exception".

Nove Noites parece ser uma busca pela reafirmação do valor da ficção. Para tanto, o romance se apropria, de maneira vertiginosa, de formas literárias que se articulam a partir de um limite mais próximo da realidade - da biografia, da autobiografia e da metaficção historiográfica , mas emprega-as de modo a fazer com que o pacto com a ficção sempre prevaleça sobre o pacto com a realidade. Este artigo tenta descrever como isto é feito.

Nove Noites é a história da pesquisa obsessiva de um jornalista sobre a razão do suicídio de Buell Quain. Quain foi um etnólogo norte-americano que realmente existiu. Aluno de Ruth Benedict na pós-graduação em antropologia da Universidade de Columbia, ele se matou enquanto pesquisava os Krahô no Xingu em agosto de 1939, aos 27 anos. O narrador de Nove Noites comprova estas e outras informações fornecidas por ele sobre o etnólogo ao longo o romance por meio de um extenso corpo documental, que inclui cartas, fotos, documentos, entrevistas e até uma pesquisa de campo. A exatidão das informações fornecidas é tal que há até informações extraídas diretamente da certidão de nascimento de Quain, como seu nome completo "Buell Halvor Quain", as data e hora exatas de seu nascimento, "31 de maio de 1912, às 11 h53 da noite" e até o hospital onde ele nasceu, "no hospital de Bismarck, capital da Dakota do Norte" (CARVALHO, 2002, p.19).

Bernardo Carvalho, autor do romance, também é jornalista. Em dois capítulos do livro (11 e 19), o narrador nos fala sobre como sua história se relaciona com a história de Quain. Sobre como, desde os seis anos de idade, ele costumava viajar durante as férias para o Xingu com o seu pai, que tinha fazendas na região. Sobre como ele visitou os Krahô acompanhado de um casal de antropólogos enquanto pesquisava sobre o suicídio de Quain. Sobre como a história de Quain se relaciona com a história da morte de seu pai, por causa de um nome - Bill Cohen - que ele ouviu da boca de um fotógrafo americano à beira da morte, que estava internado na mesma clínica que seu pai, no leito ao lado. 
Além disso, na orelha da contracapa do livro, onde geralmente encontramos uma foto do autor seguida de uma pequena descrição biográfica, vemos a foto em preto e branco de um menino de camisa, calça comprida e botas, de mãos dadas com um índio semi-nu. Embaixo da foto, uma legenda nos informa: "O autor, aos seis anos, no Xingu". Só embaixo da legenda lemos a breve biografia de Bernardo Carvalho.

Depois do final do livro, uma seção intitulada "Agradecimentos" é introduzida pelas seguintes palavras: "Este é um livro de ficção, embora esteja baseado em fatos, experiências e pessoas reais. É uma combinação de memória e imaginação - como todo romance, em maior ou menor grau, de forma mais ou menos direta" (CARVALHO, 2002, p.169).

Em Reading Autobiography: A Guide for Interpreting Life Narratives, Sidonie Smith e Julia Watson (2001) definem e diferenciam o que elas consideram formas de "escrita de vida": a biografia, a autobiografia, o romance e a história.

Biografias seriam documentos e interpretações da vida de outras pessoas a partir de um ponto de vista externo ao biografado, sem a possibilidade de uma perspectiva interna. Elas podem ser escritas durante a vida ou após a morte do biografado, necessariamente em terceira pessoa. Biógrafos incluem em seus textos múltiplas formas de evidência, incluindo documentos históricos, entrevistas e arquivos familiares. Poucos são os que empregam suas memórias pessoais a respeito de seu biografado como evidência confiável, a menos que os dois tenham tido uma relação íntima. Mesmo assim, há textos que podem apresentar uma forma híbrida, combinando biografia e autobiografia.

A distinção entre a autobiografia e o romance é complicada, pois ambos compartilham de características geralmente associadas com a escrita ficcional, como enredo, diálogo, cenário e caracterização. Além disso, muitos escritores contemporâneos estão interessados no borramento das fronteiras entre os dois gêneros. Um sinal que ajuda a diferenciar o romance da autobiografia é quando o nome do autor na capa difere do nome do personagem que narra a história (e aqui Smith e Watson citam o "pacto autobiográfico" de Philippe Lejeune, ao qual voltarei em seguida). Além disso, o romance é pautado só pela "expectativa do leitor de consistência interna no mundo da verossimilhança criado dentro do romance". Ele não necessita apresentar evidências que liguem o "mundo da narrativa ao mundo histórico fora" dela (SMITH; WATSON, 2001, p. 9).

Narradores autobiográficos, Smith e Watson (2001) concluem, estabelecem com seus leitores um pacto diferente, um conjunto de expectativas diferentes do que aquelas estabelecidas pela "verossimilhança ou a suspensão de descrença do romance ou da evidência verificável" típica da escrita histórica ou biográfica (SMITH; WATSON, 2001, p. 12).

$\mathrm{Na}$ sua teoria do pacto autobiográfico, Philippe Lejeune apresenta um conceito que integra tanto leitores ideais quanto leitores reais no processo de produção de significado da escrita autobiográfica. Para ele, a relação entre autor e leitor na autobiografia é um contrato. "O que define a autobiografia para aquele que a está lendo é acima de tudo um contrato de identidade selado pelo nome próprio. E isso também é verdade para aquele que está escrevendo o texto". Além disso, as estatísticas vitais do autor, como a data e o local de nascimento e a educação também devem ser iguais àquelas do narrador (LEJEUNE, 1989, p. 19-20). Em "The Autobiographical Pact (bis)", Lejeune reconhece que há a possibilidade do leitor real "adotar modos de leitura diferentes daquele que é sugerido a ele", uma vez que "tantos textos publicados não incluem um contrato explícito". Mas de qualquer forma, mesmo depois desta ressalva, a necessidade do pacto autor-leitor ainda permanece central neste gênero (LEJEUNE, 1989, p. 126).

Nove Noites é uma interpretação da vida de Quain feita pelos narradores da história em sua busca pela solução do mistério que o suicídio do etnólogo representa para eles. É a narrativa da vida de Quain após a sua morte, através de dois narradores em primeira pessoa, Manoel Perna, o engenheiro que recebeu Quain no Mato Grosso do Sul, e o narrador cujo nome não conhecemos, mas cuja biografia se assemelha à de Carvalho. Apesar de se assemelhar em tema e tempo àquele modelo de biografia proposto acima por Smith \& Watson (2001), o romance não se assemelha em perspectiva. As memórias pessoais dos narradores sobre Quain e sobre si se imiscuem 
às múltiplas evidências documentais verificáveis, das quais teremos muitos exemplos ao decorrer da argumentação deste artigo. Além disso, o texto todo se caracteriza pela busca pela reconstituição do ponto de vista interno de Quain, pela busca pela razão misteriosa que teria motivado seu suicídio.

Veremos agora como Nove Noites lida com os elementos constitutivos da autobiografia.O primeiro capítulo do romance, um dos nove capítulos de Manoel Perna, começa assim:

Isto é para quando você vier. É preciso estar preparado. Alguém terá que preveni-lo. Vai entrar numa terra em que a verdade e a mentira não têm mais os sentidos que o trouxeram até aqui. [...] A verdade está perdida entre todas as contradições e os disparates. Quando vier à procura do que o passado enterrou, é preciso saber que estará às portas de uma terra em que a memória não pode ser exumada, pois o segredo, sendo o único bem que se leva para o túmulo, é também a única herança que se deixa aos que ficam, como você e eu, à espera de um sentido, nem que seja pela suposição do mistério, para acabar morrendo de curiosidade. Virá ancorado em fatos que até então lhe terão parecido incontestáveis. [...]

Seja bem-vindo. [...] Vão lhe dizer muitas coisas. Sei o que espera de mim. E o que deve estar pensando. Mas não me peça o que nunca me deram, o preto no branco, a hora certa. Terá que contar apenas com o imponderável e a precariedade do que agora lhe conto, assim como tive que contar com o relato dos índios e a incerteza das traduções do professor Pessoa. As histórias dependem antes de tudo da confiança de quem as ouve, e da capacidade de interpretá-las. E quando vier você estará desconfiado. (CARVALHO, 2002, p. 7-8)

A interlocução é estabelecida desde a primeira frase do romance. "Você", neste caso, é tanto o destinatário do testamento deixado por Manoel Perna e da oitava carta deixada por Quain antes de se suicidar - que Perna teve medo de entregar de outra forma que não em mãos - quanto o leitor.

A vontade do autor de propor um pacto também é clara desde estas linhas. Ele dá boasvindas ao leitor, estabelece como ele se sentirá - "você estará desconfiado" - ao entrar nesta terra do romance - "uma terra em que a verdade e a mentira não têm mais os sentidos que o trouxeram até aqul" -, estabelece as premissas sobre as quais ele realizará sua leitura - "a memória não pode ser exumada, pois o segredo, sendo o único bem que se leva para o túmulo, é também a única berança que se deixa aos que ficam, como você e eu, à espera de um sentido" -, e pede pela sua confiança - "As histórias dependem antes de tudo da confiança de quem as ouve, e da capacidade de interpretá-las" (CARVALHO, 2002, p. 7-8).

O leitor é convocado a participar de forma ativa do romance desde o início e este convite é reiterado ao longo de todo o romance: "Isto épara quando você vier. O que eu sei é o que ele me contou e o que imaginei. [...] Só você pode entender o que quero dizer, pois tem a chave que me falta. Só você tem a outra parte da bistória" (CARVALHO, 2002, p. 122).

No segundo capítulo, narrado pelo jornalista, ele nos conta sobre como numa manhã de sábado ele leu num artigo o nome de Buell Quain e se lembrou de que já o tinha ouvido antes. Decide, então, procurar a antropóloga que o havia escrito:

Supôs que eu quisesse escrever um romance, que meu interesse fosse literário, e eu não a contrariei. A história era realmente incrível. [...] Foi ela quem me indicou as primeiras pistas. Os papéis estão espalhados em arquivos no Brasil e nos Estados Unidos. Fiz algumas viagens, alguns contatos, e aos poucos fui montando um quebra-cabeça e criando a imagem de quem eu procurava. (CARVALHO, 2002, p.14, grifo nosso)

A partir das palavras dos nossos dois narradores, vemos que a atmosfera criada entre leitor e autor nestas páginas iniciais parece ser uma de colaboração e desconfiança. É a atmosfera de uma história de detetive, da busca pela solução de um mistério através da coleção de pistas que se espalham por diversos locais e que se encaixam como num quebra-cabeça. É a este jogo que o leitor é convidado a participar. É só ele quem tem a chave.

O pacto proposto parece ser um pacto pelo jogo da ficção e não um pacto autobiográfi-

https://periodicos.unifap.br/index.php/letras

Macapá, v. 9, n. 2, $2^{\circ}$ sem., 2019 
co. Ao afirmar, no final da história, como já citei, que "[e]ste é um livro de ficção, embora esteja baseado em fatos, experiências e pessoas reais. É uma combinação de memória e imaginação - como todo romance, em maior ou menor grau, de forma mais ou menos direta", o autor se nega a assinar um pacto autobiográfico. Entretanto, vimos como um pacto é, de fato, proposto no romance (CARVALHO, 2002, p.169).

Contudo ele só declara isto depois da história já contada. Tal ambiguidade também está presente no nível formal do romance, se fazendo notar através do forte emprego de recursos narrativos pertencentes à linguagem auto/biográfica. Documentos, cartas (incluindo as cartas suicidas de Quain), entrevistas, fotos, artigos de jornal, até uma pesquisa de campo são incorporados ao romance da mesma forma que o discurso biográfico ou histórico o faria. Há menções a datas completas, locais específicos, nomes e sobrenomes. Toda a biografia de Quain e de sua família é exposta de forma detalhada e minuciosa.

A ambiguidade de Carvalho pode levar seu leitor a adotar um modelo de leitura diferente daquele sugerido pelo autor, conforme afirma Lejeune (1989) em "The Autobiographical Pact (bis)". Como toda obra pós-moderna, Nove Noites questiona as convenções destes gêneros de escrita de vida de dentro, utilizando sua linguagem para representar uma história que é ao mesmo tempo fortemente baseada em evidências e extremamente carregada de invenção.

Desta forma, percebemos como o arquivo em Nove Noites se oferece simultaneamente como fonte de evidências que comprovam a veracidade do que o narrador nos conta e como fonte de pistas para a solução do mistério. O efeito de veracidade que seu uso produz tem sua condição de efeito exposta em vários momentos do romance.

Um dos momentos mais críticos é o momento em que o autor nos conta que o testamento de Manoel Perna e a oitava carta suicida de Quain foram inventados por ele para que ele pudesse dar sentido à história. Sua invenção vai sendo confessada aos poucos, em formas de pistas. Logo no início do romance o narrador nos diz que: "No início, deixei-me levar pela suposição fácil de que aquela só podia ter sido uma morte passional e concentrei minha busca nestes vestígios. [...] Tinha que haver uma carta em que ele revelasse os seus desejos e sentimentos" (CARVALHO, 2002, p. 27).

Mais tarde, frustrado por não conseguir resolver o mistério, cansado de buscar pistas em vão, o narrador afirma a necessidade da existência de uma oitava carta. Tal carta traria à luz uma razão oculta, que ele não conseguiu encontrar nas quatro cartas suicidas de Quain a que teve acesso, mas que ele também não acreditava que estivesse numa das três cartas que ele não conseguiu recuperar:

Para mim, a resposta só podia estar numa das cartas que escreveu antes de morrer, as quais desapareceram com os seus destinatários. Ainda assim, me parecia pouco provável que, se houvesse uma explicação numa das cartas que o etnólogo deixou ao pai, ao cunhado ou ao missionário Thomas Young, ela pudesse não ter vindo a público. Foi quando comecei a acalentar a suposição de que devia haver (ou ter havido) uma oitava carta. (CARVALHO, 2002, p. 114)

Logo em seguida, o narrador justifica sua atitude inventiva ao comentar sobre a natureza da atribuição de sentido feito por qualquer leitor ao discurso da literatura: "Cada um lê os poemas como pode e neles entende o que quer, aplica o sentido dos versos à sua própria experiência acumulada até o momento em que os lê" (CARVALHO, 2002, p. 114). Vinte páginas depois, este mesmo narrador admite que "Manoel Perna não deixou nenhum testamento, e eu imaginei a oitava carta". (CARVALHO, 2002, p. 134)

Esta declaração destrói, de maneira certeira, a confiança do leitor. Se as nove partes do testamento de Manoel Perna são ficção, se, na verdade, as cartas sempre foram só sete, qualquer outro documento pode ter sido inventado e qualquer outro documento não-inventado pode ter sido manipulado para que contribuísse para a construção do sentido que o autor buscava.

Traços desta arbitrariedade da atribuição de sentido ao discurso do passado por aquele 
que o narra estão presentes desde antes no romance. Um exemplo é o trecho em que o narrador fala sobre o nome indígena que foi dado a Quain pelos Krahô, "Cãmtwỳon":

\begin{abstract}
"O que significa?”, eu queria saber. Mas ninguém sabia ao certo. [...] Passei o resto da viagem tentando encontrar alguém que me decifrasse o significado daquele nome. Dois dias depois, quando chegamos à aldeia, [...] o casal mais ativo e interessado no estudo da própria língua [...], me disseram que "twỳon" queria dizer lesma, caracol e seu rastro. O antropólogo já havia me dito que "cãm" era o presente, o aqui e o agora, mas ninguém conseguia saber o sentido da combinação daquelas duas palavras. $\mathrm{O}$ antropólogo me explicou que, ao contrário do que costumam pensar os brancos, os nomes dos índios nem sempre querem dizer alguma coisa e sobretudo nada têm a ver com a personalidade da pessoa nomeada. Fazem parte de um repertório e são atribuídos ao acaso. Eu teria que voltar para São Paulo sem saber o que significava aquele nome. Mas não conseguia aceitar que não revelasse alguma coisa sobre o próprio Quain, que não houvesse nenhuma relação entre o nome e a pessoa. Decidi-me por uma interpretação selvagem e um tanto moral: "Cãmtwỳon" passou a ser, para mim, ao mesmo tempo a casa do caracol e o seu fardo no mundo, a casca que ele carrega onde quer que esteja e que também lhe serve de abrigo, o próprio corpo, do qual não pode se livrar a não ser com a morte, o seu aqui e o seu agora para sempre. "Cãmtwỳon" passou a ser para mim o rastro do caracol: não adianta fugir: aonde quer que você vá estará sempre aqui. (CARVALHO, 2002, p. 80-81)
\end{abstract}

Mesmo depois do antropólogo ter lhe dito que um nome indígena não significava necessariamente coisa alguma, que isso era uma suposição errada dos brancos, que os nomes indígenas geralmente não queriam dizer nada sobre a personalidade da pessoa batizada, ele teve que atribuir um sentido ao nome de Quain, um sentido que conviesse aos rumos que ele tentava estabelecer para a solução do mistério, que lhe ajudasse a compor esta narrativa.

É o uso da metaficção que ajuda Carvalho a mostrar que o arquivo não é um meio transparente de acesso direto passado, mas sim seu rastro textualizado. Nove Noites mostra como documentos, entrevistas, fotos e cartas não são "repositórios da verdade", mas "representações", textos que são processados por historiadores e biógrafos, conscientemente compostos por eles numa ordem narrativa de forma a atribuir sentido ao passado (HUTCHEON, 1989, p. 86).

Através da invenção deliberada da carta e do testamento, e da atribuição arbitrária de sentido ao nome indígena de Quain, Nove Noites "brinca com as verdades e as mentiras do discurso histórico", enfatizando "as possíveis falhas mnemônicas" da história e o seu "constante potencial para um erro deliberado ou inadvertido". O romance também chama nossa atenção para o paradoxo que há entre "a realidade do passado e a acessibilidade exclusivamente textualizada" que temos a ele hoje (HUTCHEON, 1988, p. 114).

Nestes aspectos, Nove Noites se assemelha muito à forma narrativa pós-moderna que Linda Hutcheon $(1988,1989)$ chama de metaficção historiográfica. Também como uma metaficção historiográfica, o romance encena o próprio processo de tentativa de assimilação de informações históricas. Há não um, mas dois narradores, perdidos em meio à busca por um sentido para os fatos que coletaram.

Outro traço que Nove Noites compartilha com a metaficção historiográfica é a tentativa de "desmarginalizar o status do literário através de sua confrontação com o histórico". Segundo Hutcheon,

"é parte da posição pós-moderna confrontar os paradoxos da representação fictícia/ histórica, particular/geral e do passado/ do presente. Esse confronto [...] se recusa a recuperar ou dissolver qualquer um dos lados da dicotomia, mas está disposto em explorar ambos". (HUTCHEON, 1988, p.106-108)

E é aí que as diferenças começam, pois, como vimos, apesar de lidar com todos estes paradoxos, Nove Noites valoriza a ficção sobre a realidade, como parte de seu projeto particular de desmarginalização do literário.

A metaficção historiográfica, como o nosso romance, parece "obcecada com a ligação entre histórias fictícias e mentirosas", mas sua preocupação tem mais a ver com "a multiplicidade e 
dispersão das verdades relacionadas com a especificidade de um lugar ou cultura" do que com a preocupação com "mentiras e falsidades". Este gênero considera que verdade e mentira não são os termos certos para a discussão da ficção, não porque a literatura é "um discurso que não pode ser submetido ao teste da verdade", mas porque "só há verdades no plural e nunca uma Verdade" (HUTCHEON, 1988, p.108-109).

Mais uma vez, não parece ser assim que as coisas funcionam em Nove Noites. Nossos narradores não aparentam estar nem um pouco preocupados seja com a Verdade absoluta ou com verdades mais particulares. Apesar de narrarem eventos históricos, eles parecem concordar que a literatura não pode ser submetida ao teste da verdade. O que realmente interessa é a ficção, a invenção. Manoel Perna nos garante repetidas vezes que "O que agora lhe conto é a combinação do que ele me contou e da minha imaginação ao longo de nove noites." (CARVALHO, 2002, p. 47). Assim, novamente, em outro capítulo, repete: "O que lhe conto é uma combinação do que ele me contou e do que imaginei. Assim também, deixo-o imaginar o que nunca poderei lhe contar ou escrever." (CARVALHO, 2002, p. 134)

Uma metaficção historiográfica geralmente apresenta "a necessidade de questionar versões recebidas da história", uma "preocupação política" com a sua "recepção, com seu leitor". Desta forma, este gênero "reinstala um tipo (muito problemático) de projeto comunal". Ela tem a preocupação de mostrar que "a ficção é historicamente condicionada e que a história é discursivamente construída", e assim, "acaba alargando o debate sobre as implicações ideológicas da conjunção foucaultiana entre poder e saber". Ela sublinha como "toda representação do passado tem implicações ideológicas específicas". Ela parece perguntar qual é a história que sobrevive: é "a história de quem", "a verdade de quem" que acaba sendo contada pela história oficial? (HUTCHEON, 1988, p. 115-123)

Novamente, nossa narrativa não se encaixa neste gênero porque ela não apresenta uma preocupação em questionar a narrativa oficial da história, ou denunciar as implicações ideológicas de toda escrita historiográfica (ou de toda narrativa de forma geral). Apesar disto, o romance levanta questões sociais sérias, como, por exemplo, a questão do diálogo entre as culturas. Há um trecho logo no início do romance em que o narrador nos conta já ter entrevistado Lévi-Strauss por duas vezes em Paris. Ele cita e comenta o que Lévi-Strauss disse numa das entrevistas:

\footnotetext{
"Quanto mais as culturas se comunicam, mais elas tendem a se uniformizar, menos elas têm a comunicar. O problema para a humanidade é que haja comunicação suficiente entre as culturas, mas não excessiva. [...]" Dizia que toda cultura tenta defender a sua identidade e originalidade por resistência e oposição ao outro, e que havia chegado a hora de defender a originalidade ameaçada da sua própria cultura. Falava da ameaça do islã, mas podia estar falando igualmente dos americanos e do imperialismo cultural anglo-saxão. (CARVALHO, 2002, p. 52-53)
}

A questão do índio no Brasil também é abordada em alguns trechos do romance. Quando ele fala do isolamento dos índios no Xingu, por exemplo:

O Xingu, em todo caso, ficou guardado na minha memória como a imagem do inferno. Não entendia o que dera na cabeça dos índios para se instalarem lá, o que me parecia de uma burrice incrível, se não um masoquismo e mesmo uma espécie de suicídio. Não pensei mais no assunto até o antropólogo que por fim me levou aos Krahô, em agosto de 2001, me esclarecer: "Veja o Xingu. Por que os índios estão lá? Porque foram sendo empurrados, encurralados, foram fugindo até se estabelecerem no lugar mais inóspito e inacessível, o mais terrível para a sua sobrevivência, e ao mesmo tempo a sua única e última condição. O Xingu foi o que lhes restou." (CARVALHO, 2002, p. 72-73)

E quando ele fala da questão da situação marginal do índio dentro da sociedade brasileira:

São os órfãos da civilização. Estão abandonados. Precisam de alianças no mundo dos brancos, um mundo que eles tentar entender com esforço e em geral em vão. (...) há neles uma carência irreparável. Não querem ser esquecidos. Agarram-se como podem a todos os que passam pela aldeia, como se os

https://periodicos.unifap.br/index.php/letras

Macapá, v. 9, n. 2, $2^{\circ}$ sem., 2019 
visitantes fosse os pais há muito desaparecidos. (...) Essa relação paternalista é das mais incômodas e irritantes, e o próprio Quain sofreu este constrangimento. Há quem tire de letra. Não foi o meu caso. Não sou antropólogo e não tenho uma boa alma. Fiquei cheio. (CARVALHO, 2002, p. 108-109)

Em ambos os casos, apesar de sua condição marginalizada, os índios não são tratados de forma paternalista. Seu problema não é abordado de maneira simplista. A situação dos índios no Brasil, mostra o narrador, não pode ser solucionada por meia dúzia de antropólogos de boa alma. Representá-la pode fazer alguma diferença, mas Carvalho parece não ter muita fé no poder político de uma literatura que aborde tais aspectos de forma central e direta. Tal atitude fica clara no trecho em que ele tenta explicar o que é a ficção para os Krahô, preocupados com a forma que ele está revirando o passado da aldeia:

Os velhos estavam preocupados, queriam saber por que eu vinha remexer no passado [...] Tentei lhe explicar que eu queria escrever um livro e mais uma vez o que era um romance, o que era um livro de ficção (e mostrava o que tinha nas mãos), que seria tudo historinha, sem nenhuma consequência na realidade. [...] Eu tentava dizer que, para os brancos que não acreditam em deuses, a ficção servia de mitologia, era o equivalente dos mitos dos índios, e antes mesmo de terminar a frase, já não sabia se o idiota era ele ou eu. Ele não dizia nada a não ser: "O que você quer com o passado?" Repetia. E, diante de sua insistência bovina, tive de me render à evidência de que eu não sabia responder à sua pergunta. Não conseguia fazê-lo entender o que era ficção (no fundo, ele não estava interessado), nem convencê-lo de que o meu interesse pelo passado não teria consequências reais, no final seria tudo inventado. (CARVALHO, 2002, p. 95-96, grifo nosso)

Nove Noites também apresenta um grande cuidado com o contexto histórico que cerca os dois momentos centrais do romance, a época em que Quain veio para o Brasil no final dos anos 1930 e a época em que nosso narrador-autor faz sua pesquisa no começo dos anos 2000. Há o trecho em que ele fala sobre sua ida aos Estados Unidos para entrevistar o filho do fotógrafo americano:

A ficção começou no dia em que eu botei os pés nos Estados Unidos. A edição do The New York. Times, de 19 de fevereiro de 2002, que distribuíram a bordo, anunciava as novas estratégias do Pentágono: disseminar notícias - até mesmo falsas, se preciso - pela mídia internacional; usar todos os meios para "influenciar as audiências estrangeiras. (CARVALHO, 2002, p. 158)

Neste trecho, é curioso notar como a mesma atitude de descaso com a verdade apresentada pelos nossos narradores parece ser compartilhada pelas autoridades americanas em consequência dos ataques de 11 de setembro.

Há, também, a relação entre o dia da morte de Quain e o início da Segunda Guerra:

Buell Quain se matou na noite de 2 de agosto de 1939 - no mesmo dia em que Albert Einstein enviou ao presidente Roosevelt a carta histórica em que alertava sobre a possibilidade da bomba atômica, três semanas antes da assinatura do pacto de não-agressão entre Hitler e Stalin, o sinal verde para o início da Segunda Guerra e, para muitos, uma das maiores desilusões políticas do século XX. (CARVALHO, 2002, p. 15)

E a caracterização do Carnaval do Rio de 1938:

no Carnaval de 1938, um dos principais personagens da mitologia local, exponente da malandragem, do crime e da homossexualidade do bairro, ganhou o concurso do baile do teatro República, próximo à praça Tiradentes, com uma fantasia de lantejoulas inspirada num morcego do Nordeste, de onde vinha, e daí em diante passou a ser chamado Madame Satã. (CARVALHO, 2001, p. 121)

Depois relacionada com a chegada de Quain no Rio neste mesmo Carnaval:

Me disse que chegou no Rio no Carnaval de 1938 e que conheceu, num bloco de rua, uma negra alta e

https://periodicos.unifap.br/index.php/letras

Macapá, v. 9, n. 2, $2^{\circ}$ sem., 2019 
vistosa, fantasiada de enfermeira. [...] Ele mal falava português. Não entendia nada que ela lhe dizia. Estava bêbado. Levou-a para o seu quarto de pensão, dormiram juntos, mas quando acordou no dia seguinte, ela já não estava lá [...] e no lugar da enfermeira havia um homem na sua cama, um negro forte e nu. (CARVALHO, 2001, p. 127)

A esta história segue-se uma outra que Quain teria lhe contado sobre um chefe de

Vanua Levu, ilha no Pacífico onde ele tinha passado um tempo pesquisando os nativos antes de sua viagem ao Brasil. A história diz respeito a um homem que seduzia todas as mulheres, um chefe que se disfarçou de mulher para pregar-lhe uma peça, o casamento entre os dois homens, dois pênis eretos que se tocam e a fuga do sedutor, perseguido pelo chefe que exigia que eles dormissem juntos.

Os três trechos acima também falam sobre uma terceira questão, a do homossexual no fim dos anos 1930. Uma situação que era definitivamente marginal e vista com um preconceito ainda maior que o de hoje pela sociedade da época. Como a questão do índio, ela não é abordada de maneira simplista, não figura como preocupação central no romance, mas é, ainda assim, levantada e debatida.

A questão central em Nove Noites é a sua própria produção. Seu pacto maior é com o mundo da verossimilhança e não com o mundo histórico fora da narrativa. Assim como a ficção é preferida sobre a autobiografia e a biografia, ela também o é sobre a metaficção historiográfica. Apesar de se apropriar da linguagem destes três gêneros, há, nos três casos, traços constitutivos fundamentais que destoam das convenções formais de maneira a sempre privilegiar a ficção. Mas, mesmo assim, apesar de Nove Noites não exibir uma preocupação em alterar a versão contada pela história oficial sobre os índios ou sobre os gays, por exemplo, a escolha pela representação destes temas não parece ter sido feita de forma gratuita. A escolha de temas narrativos tão relevantes só ajuda a corroborar o lugar central ocupado pela ficção neste romance.

O privilégio concedido à ficção, a encenação da "produtividade", o contraste entre "a realidade do mundo e a realidade da ficção", a instalação de "dois âmbitos" distintos e a transformação do limite que os separa num "labirinto" ou num "jogo de espelhos" - traços muito fortes em Nove Noites - me levaram, no decorrer desta pesquisa, na direção da literatura fantástica. É claro que a metaficcionalidade e a erudição irônica deste romance tem muito de Jorge Luis Borges, é claro que sua concepção da literatura como jogo tem muito de Julio Cortázar, mas o que mais me impressiona foi perceber que hoje estamos tão envoltos neste discurso da memória que qualquer obra que privilegie um pacto com a ficção a um com a realidade acaba nos parecendo fantástica (BRAVO, 1987, p.26-47).

Vivemos uma época em que "os vivos são sempre e cada vez, mais governados pelos mortos" (CARVALHO, 2002, p. 127). Estamos com uma febre de arquivo, sofremos deste mal, ardemos nesta paixão. Apresentamos "um desejo compulsivo, repetitivo, nostálgico" e irreprimível pelo arquivo. Nunca nos cansamos de procurá-lo exatamente onde ele nos foge. (DERRIDA, 1995, p. 57)

É deste mal que o narrador de Nove Noites sofre e é dele que ele tenta se livrar. Na última cena do romance, no avião de volta de Nova Iorque, depois de descartada a última hipótese sobre a razão do suicídio de Quain, um estudante americano se senta ao lado do narrador e lhe diz que está indo estudar os índios do Brasil. O narrador não responde:

Não consegui dizer mais nada. [...] Nessa hora, me lembrei sem mais nem menos de ter visto uma vez,
num desses programas de televisão sobre as antigas civilizações, que os Nazca do deserto do Peru
cortavam as línguas dos mortos e as amarravam num saquinho para que nunca mais atormentassem os
vivos. Virei para o outro lado e, contrariando a minha natureza, tentei dormir, nem que fosse só para calar os
mortos. (CARVALHO, 2002, p. 167-168, grifo nosso)

Há ainda mais uma semelhança entre Nove Noites e a literatura fantástica. O livro de Victor Bravo - teórico que consultei em busca de explicações sobre a literatura fantástica - se chama, curiosamente, Los poderes de la ficción. Para Bravo, como para Carvalho, opoder da literatura parece 
residir na ficção, "na invenção do que ainda tem que ser criado", não "na representação do que já reconhecemos ao nosso redor" (CARVALHO, 2010, p.9).

Vimos que, em Nove Noites, a realidade não é capaz de dar conta do mistério. Depois de levantadas e refutadas todas as hipóteses acerca da razão do suicídio de Quain - uma relação incestuosa com a irmã, sífilis, sofrimento com a sua condição homossexual -, nenhuma solução pode ser oferecida. Esgotadas todas as fontes, nunca saberemos por que Buell Quain se matou. Não há onde procurar. A verdade, como a memória, não pode ser recuperada.

\section{Referências}

BRAVO, Victor. Los poderes de la ficción. Caracas: Monte Avila Editores, 1987.

CARVALHO, Bernardo. Nove noites. São Paulo: Companhia das Letras, 2004.

CARVALHO, Bernardo. "Bernardo Carvalho e a literatura como antídoto da banalidade": depoimento. [30/08/2011]. Disponível em: http://dw.de/p/12PlJ. Acesso em: 10/06/2019.

CARVALHO, Bernardo. "Fiction as Exception”. In: Luso-Brazilian Review, Volume 47, Number 1, 2010, pp. 1-10.

CARVALHO, Bernardo. "Entrevista com Bernardo Carvalho": depoimento. Blog da Companbia [30/01/2013]. Disponível em: http://www.blogdacompanhia.com.br/2013/01/entrevista-combernardo-carvalho/. Acesso em: 10/06/2019.

DERRIDA, J. "Archive Fever: A Freudian Impression". In: Diacritics, Vol. 25, No 2. (Summer, 1995), pp. 9-63.

HUTCHEON, Linda. A Poetics of Postmoderdenism: History, Theory, Fiction. London: Routledge, 1988.

HUTCHEON, Linda. The Politics of Postmodernism. London: Routledge, 1989.

HUYSSEN, Andreas. Memórias do modernismo. Rio de Janeiro: Editora UFRJ, 1997.

HUYSSEN, Andreas. Present Pasts: Urban Palimpsests and the Politics of Memory. Stanford: Stanford University Press, 2003.

LEJEUNE, Philippe. On Autobiography. Ed. Paul John Eakin, trans. Katherine Leary. Minneapolis: University of Minnesota Press, 1989.

SMITH, Sidonie; WATSON, Julia. Reading Autobiography: a Guide for Interpreting Life Narratives. Minneapolis: University of Minnesota Press, 2001.

Envio: 30/08/2019

Aceite: 08/11/2019 